Artigo original

Hegemonia - Revista Eletrônica de Relações Internacionais do Centro Universitário Unieuro

ISSN: $1809-1261$

UNIEURO, Brasília, número 11, 2013, pp. 36-68

Recebido em: 19/1/2013

Revisado em: 24/1/2012

Aprovado em: 14/2/2013

\title{
A JURIDICIZAÇÃO DO ÓRGÃO DE SOLUÇÃO DE CONTROVÉRSIAS DA OMC E A PROMOÇÃO DO DESENVOLVIMENTO SUSTENTÁVEL
}

ALVES, Gleisse Ribeiro ${ }^{1}$ e OLIVEIRA, Liziane Paixão Silva²

Resumo: Os procedimentos de promoção do desenvolvimento sustentável são complexos e fragmentados. Um dos novos temas discutido no âmbito internacional é a relação entre comércio e desenvolvimento sustentável. $O$ presente artigo tem por objetivo examinar como a OMC por meio do Órgão de Solução de Controvérsias (OSC) tem contribuído para a realização desse desenvolvimento sustentável. Assim, serão analisados os princípios que regem o OSC bem como os aspectos formadores de sua natureza jurisdicional. Por fim, o artigo analisará por meio da implementação das decisões do OSC como na prática esse órgão pode contribuir para a promoção do desenvolvimento sustentável.

1 Doutora em Direito pela Universidade Nancy 2 - França ( Tese indicada ao prêmio de melhor tese do ano de 2011); Mestre em Direito das Relações Internacionais pelo UniCEUB; Graduada em Relações Internacionais pela Universidade Católica de Brasília.

2 Possui graduação em Direito pela Universidade Tiradentes (2002), Pósgraduação em Direito Ambiental pelo UniCEUB (2004), Mestrado em Direito pela Universidade de Brasília (2006), Doutorado na Universidade Aix-Marseille III, na França (2012). 
Artigo original

Hegemonia - Revista Eletrônica de Relações Internacionais do Centro Universitário Unieuro

ISSN: $1809-1261$

UNIEURO, Brasília, número 11, 2013, pp. 36-68

Palavras-chave: OMC; Solução de controvérsias; Comércio; Desenvolvimento sustentável.

Abstract: The procedures of the sustainable development promotion are complex and fragmented. One of the new subject-matters that has been discussed in the international scope is the relation between trade and sustainable development. The current article aims at examining how the World Trade Organization (WTO), through its Dispute Settlement Body (DSB), has contributed to the accomplishment of that sustainable development. Therefore, the principles that rule the DSB will be analyzed as well as the aspects that form its jurisdictional nature. Ultimately, the article will analyze through the implementation of the DSB decisions how, in fact, this body can contribute to the promotion of the sustainable development.

Keywords: WTO; Dispute Settlement; Trade; Sustainable Development.

1 Introdução

Embora o termo "desenvolvimento sustentável" seja amplamente utilizado, as definições do que venha a ser o desenvolvimento sustentável ainda não estão claramente sedimentadas na literatura especializada. Uma autora afirma que "para alguns estudiosos, alcançar o desenvolvimento sustentável é obter o crescimento econômico contínuo através de um manejo mais racional dos recursos naturais e da utilização de tecnologias mais eficientes e menos poluentes. Para outros, o desenvolvimento sustentável é antes de tudo um projeto social e político destinado a 
Artigo original

Hegemonia - Revista Eletrônica de Relações Internacionais do Centro Universitário Unieuro

ISSN: $1809-1261$

UNIEURO, Brasília, número 11, 2013, pp. 36-68

erradicar a pobreza, elevar a qualidade de vida e satisfazer às necessidades básicas da humanidade". 3

Os procedimentos de implementação do desenvolvimento sustentável são complexos e fragmentados. Essa complexidade se expressa, dentre outros fatores, pelo grande número de atores que atuam na realização de um meio ambiente saudável: governos nacionais, ONGs, associações, organizações internacionais, dentre outros. Várias são também as áreas com as quais as questões ambientais estão relacionadas: política, econômica, comercial, jurídica, sociológica, etc. Além desses aspectos, convém ressaltar o fato de que os problemas ambientais são cada vez mais globalizados e que, portanto, demandam atitudes e tomadas de decisão internacionais.

Dessa forma, há uma crescente interação entre o direito nacional e o internacional na aplicação das políticas ambientais. Uma das principais preocupações correntes reside na aproximação entre o direito do comércio internacional e a promoção do desenvolvimento sustentável.

\footnotetext{
3 SEIFFERT, Mari Elizabete Bernardini. Gestão ambiental : instrumentos,
} esferas de ação e educação ambiental. São Paulo: Atlas, 2011, p. 24. 
Artigo original

Hegemonia - Revista Eletrônica de Relações Internacionais do Centro Universitário Unieuro

ISSN: $1809-1261$

UNIEURO, Brasília, número 11, 2013, pp. 36-68

Para alguns autores meio ambiente e comércio caminham em lados opostos, pois esses acreditam que regras ambientais constituem muitas vezes obstáculos ao livre comércio. Outros, porém, acreditam na relação complementar que possa existir entre meio ambiente e comércio ${ }^{4}$. A Organização Mundial do Comércio (OMC) é o grande exemplo da complementaridade existente entre comércio e normas ambientais. Embora a OMC não tenha um acordo específico versando sobre meio ambiente, esse tema está cada vez mais presente nas relações comerciais discutidas no âmbito dessa organização.

Face à atuação cada vez mais presente da OMC no contexto ambiental o presente estudo pretende examinar como a juridicização do Órgão de Solução de controvérsias da OMC pode promover a implantação do desenvolvimento sustentável.

A partir da estrutura da OMC, pode-se perceber que o Orgão de Solução de Controvérsias (OSC) é na prática aquele capaz de apreciar

\footnotetext{
Mais comentários sobre essa relação ver VARELLA, Marcelo Dias. O acúmulo de lógicas distintas no Direito Internacional: conflitos entre comércio internacional e meio ambiente. IN Desafios do direito ambiental no século XXI, 2005. PIRES, Camila Faria Braga. Comércio e meio ambiente e a Organização Mundial do Comércio. Revista Eletrônica de Direito Internacional (CEDIN), 2007, Disponível em: <http://www.cedin.com.br/revistaeletronica/indice.htm>, acesso em 24 abr. 2012.
} 
Artigo original

Hegemonia - Revista Eletrônica de Relações Internacionais do Centro Universitário Unieuro

ISSN: $1809-1261$

UNIEURO, Brasília, número 11, 2013, pp. 36-68

e aplicar quase todas as normas atinentes ao comércio internacional oriundas da OMC. Em outras palavras, o OSC com seu secretariado, orçamento e procedimentos jurídicos próprios dispõe de uma estrutura capaz de zelar pela correta aplicação dos princípios e dos Acordos da OMC. Será analisado nas linhas a seguir quais os princípos que norteiam o OSC (2), se o mesmo apresenta os requisitos necessários capazes de qualificá-lo como órgão jurisdicional (3) e de que forma essa função jurisdicional pode promover o desenvolvimento sustentável, na prática. (4).

2 Princípios que regem o OSC

A resolução de litígios no âmbito da OMC é realizada pelo Órgão de Solução de Controvérsias (OSC). Embora o OSC tenha ainda algumas semelhanças com o GATT 1947, como por exemplo, o fato de possuir procedimentos diplomáticos e jurisdicionais, ele é um instrumento marcante da originalidade e da peculiaridade da OMC.

Ao contrário do que ocorria com as regras do GATT de 1947, o sistema de resolução de litígios no âmbito da OMC é revestido de 
Artigo original

Hegemonia - Revista Eletrônica de Relações Internacionais do Centro Universitário Unieuro

ISSN: $1809-1261$

UNIEURO, Brasília, número 11, 2013, pp. 36-68

dispositivos obrigatórios. Esses possibilitam o cumprimento das obrigações previstas no âmbito dos acordos da OMC e, assim, podem proporcionar uma maior segurança ao sistema mulilateral. A reforma do sistema de solução de controvérsias do GATT de 1947 deu-se com o acordo "Entendimento Relativo às Normas e Procedimentos sobre Solução de Controvérsias" (ESC). Ao abrigo deste regime interno, os litígios entre os Membros da OMC serão submetidos ao OSC.

Todo órgão criado para exercer a função jurisdicional é capaz de criar regras jurídicas e aplicá-las, e deve estar revestido de certos requisitios. Alguns órgãos tendem a aplicar esses requisitos já na sua organização interna e outros, os aplicam ao exercer a competência que Ihes foi atribuída.

Os órgãos jurisdicionais nacionais são normamente caracterizados por uma estrutura do tipo piramidal. Ou seja, é composto por jurisdições inferiores e de apelação. Um pouco diferente é a ordem internacional que se caracteriza por ter estruturas jurídicas do tipo horizontal. Quer dizer, ausência de órgãos supremos capazes de criar uma subordinação dos demais. Essa configuração internacional é, portanto, a que perdura na estrutura do OSC da OMC. 
Artigo original

Hegemonia - Revista Eletrônica de Relações Internacionais do Centro Universitário Unieuro

ISSN: $1809-1261$

UNIEURO, Brasília, número 11, 2013, pp. 36-68

Assim, logo que surge um litígio entre membros da OMC qualquer um dos envolvidos no conflito podem reclamar o caso perante o secretariado do Órgão de Solução de Controvérsias. O OSC designará a instalação de um Grupo especial (painel) que analisará o litígio e emitirá um relatório encerrando-se assim as atividades do Grupo especial formado apenas para avaliação do caso específico. Esse Grupo especial é constituído por três pessoas (as vezes cinco, se as partes envolvidas no conflito assim solicitarem), escolhidas a partir de uma lista constando o nome de especialistas indicados por todos os Membros da OMC. Esses especialistas são oriundos das diversas áreas do conhecimento com experiência principalmente nos temas relacionados ao direito, política comercial e internacional ${ }^{5}$. As qualidades de magistrados não necessariamente estarão presentes nesses especialistas e, portanto, eles não prestam juramento no momento da sua inscrição nas listas nem quando exercem as funções de árbitros no momento do litígio.

Assim, o Grupo especial é formado no momento que surge o litígio tendo, portanto, características ad hoc. No entanto, o Órgão de Controvérsias (ESC), artigo 8. 
Artigo original

Hegemonia - Revista Eletrônica de Relações Internacionais do Centro Universitário Unieuro

ISSN: $1809-1261$

UNIEURO, Brasília, número 11, 2013, pp. 36-68

apelação é permanente. Seus membros são sete e estes são magistrados designados a partir de proposições dos membros da OMC. A escolha dos membros do Órgão de apelação ocorre nas Conferências Ministeriais e são designados para um mandato de quatro anos com possibilidade de renovação.

Ao serem empossados nas funções de membros do Órgão de apelação, os escolhidos não prestam necessariamente juramento, mas, um discurso proferido na Conferência Ministerial comprometendo-se a bem realizar as tarefas que the forem submetidas. Além disso, os membros do Órgão de apelação obrigamse a realizar as tarefas com imparcialidade e com extrema competência para bem cumprir os acordos comerciais. Ao final dos quatro anos, em caso de reeleição esse discurso é novamente proferido.

Ao longo dos anos, os trabalhos no Órgão de apelação são cada vez maiores devido ao grande número de litígos apresentados ao OSC e principalmente à complexidade dos mesmos. Evidencia-se a necessidade de uma reestrutuação e um aumento dos membros do Órgão de apelação. 
Artigo original

Hegemonia - Revista Eletrônica de Relações Internacionais do Centro Universitário Unieuro

ISSN: $1809-1261$

UNIEURO, Brasília, número 11, 2013, pp. 36-68

Nos litígios conduzidos pelo Órgão de Solução de Controvérsias (OSC), a presença de especialistas é cada vez mais frequente, tanto nos Grupos especiais como no Órgão de apelação. O apêndice 4 do ESC determina como ocorre a organização e a participação de especialistas no OSC. Esses indivíduos ou organizações dotados de conhecimentos especiais e reconhecidos por seu notório saber profissional são competentes em determinados domínios, e acabam auxiliando o OSC na tomada de decisão. Eles participam do Órgão na qualidade de especialistas e estudiosos em determinados temas a serem debatidos e, como prestam serviços ao OSC eles devem agir com imparcialidade e não podem representar nenhuma das partes envolvidas no conflito. Esses experts têm acesso a todas as fontes, mesmo que sigilosas (respeitando as devidas exigências de não divulgação), que julgarem necessárias e apropriadas para o aconselhamento técnico a ser dado ao OSC. Assim o grupo consultivo, formado pelos experts, redige um parecer (não vinculativo) sobre as demandas do OSC. Esses relatórios são anexados ao relatório final do Grupo especial.

Convém ressaltar que no âmbito do OSC não existe a figura do "Ministério Público". Assim, nenhum órgão ou operador privado 
Artigo original

Hegemonia - Revista Eletrônica de Relações Internacionais do Centro Universitário Unieuro

ISSN: $1809-1261$

UNIEURO, Brasília, número 11, 2013, pp. 36-68

pessoalmente poderá provocar o OSC alegando o conhecimento de práticas empresariais que violem os princípios básicos defendidos pela OMC. Quanto à provocação do Órgão de apelação, esta é pertinente somente quando apresentada pelo membro competente. Isto é, o membro envolvido no litígio que julgar desfavorável o parecer do Grupo especial. Assim pode-se submeter o relatório do Grupo especial à apreciação do Órgão de apelação.

3 Natureza jurisdicional do OSC

A ordem internacional tem presenciado cada vez mais, o a multiplicação de organismos revestidos de funções jurídicas ${ }^{6}$. É possível reconhecer que as decisões por eles emanadas são atos jurídicos? A responsabilidade de resolver litígios é o bastante para dar à instituição um caráter jurisdicional? Mais especificamente, o fato de possuir juízes, litigantes, uma sala para audiências, um rito processual simbólico é o suficiente para a identificação de um órgão jurisdicional? Doutrinadores definem que um órgão é revestido do

6 Mais detalhes ver: DUPUY Pierre-Marie, L'unité de l'ordre juridique international, Recueil des cours - Académie de Droit International de La Haye, 2002, T.297, p. 33-34. 
Artigo original

Hegemonia - Revista Eletrônica de Relações Internacionais do Centro Universitário Unieuro

ISSN: $1809-1261$

UNIEURO, Brasília, número 11, 2013, pp. 36-68

caráter jurisdicional quando este é capaz de cumprir três exigências: primeiro ele deve ser capaz de aplicar a lei; segundo, ser capaz de pôr fim ao litígio e finalmente, ter a capacidade de emitir decisões obrigatórias7 ${ }^{7}$ Em relação ao OSC da OMC, a questão é dupla. Devemos, primeiramente, examinar o problema de natureza jurídica das decisões emanadas pelo OSC (3.1 e 3.2), para em seguida, discutir as modalidades de implementação das recomendações ou decisões do OSC (4).

3.1 Da função política à juridicização do OSC

A ordem internacional é estruturada em regime de governança fundamentado em normas convencionais elaboradas por instituições intergovernamentais ou supranacionais incumbidas da aplicação das obrigações impostas pelos tratados. Assim, essa governança ocorre muitas vezes com a transferência de poderes do Estado a outros

7 Cf. SANTULLI Carlo, Qu'est-ce qu'une juridiction internationale? Des organes répressifs internationaux à I'ORD, Annuaire Français de droit international, 2000, Vol. XLVI, p. 58-81; D'AMBRA Dominique. L'objet de la fonction juridictionnelle, dire le droit et trancher les litiges. Paris : Librairie générale de droit et de jurisprudence, 1994 ; CAVARÉ L, La notion de juridiction internationale. Annuaire Français de droit international, 1956, p. 496-509. 
Artigo original

Hegemonia - Revista Eletrônica de Relações Internacionais do Centro Universitário Unieuro

ISSN: $1809-1261$

UNIEURO, Brasília, número 11, 2013, pp. 36-68

órgãos internacionais. Cabe lembrar que a governança deve gerar credibilidade e previsibilidade na aplicação das regras.

Observa-se, porém, que a governança internacional é marcada por uma perspectiva política que geralmente apresenta menos credibilidade o que provoca a incerteza, a instabilidade e a ausência de legitimidade ${ }^{8}$. Ninguém duvida que, além da questão econômica, os interesses políticos são o fundamento da Organização Mundial do Comércio. Cabe, porém ressaltar que para a evolução e mesmo manutenção da OMC deve-se existir uma unidade entre os membros e o respeito aos acordos assinados. Essa unidade é materializada pela conclusão das negociações realizadas principalmente por meio das Rodadas.

Na prática, a construção de um processo capaz de garantir legitimidade ocorre pela presença de três elementos principais: existência de um sistema normativo, vontade das partes em cooperar na validação das normas e por fim, a presença de um terceiro capaz de agir com imparcialidade ${ }^{9}$.

\footnotetext{
Sobre juridicização ver: REICH Arie, From diplomacy to law: the juridicization of international trade relations, Northwestern Journal of International Law and Business, 1996-1997, n 17, p. 831-839.

9 SWEET Stone, Judicialization and the construction of governance, Comparative Political Studies, 1999, Vol. 32, n² 2, p. 147-184.
} 
Artigo original

Hegemonia - Revista Eletrônica de Relações Internacionais do Centro Universitário Unieuro

ISSN: $1809-1261$

UNIEURO, Brasília, número 11, 2013, pp. 36-68

Verifica-se cada vez mais a gradual passagem de órgãos que apresentam uma estrutura flexível fundamentado em regras diplomáticas para um regime mais rígido baseado em restrições legais cada vez mais próximos da aplicação e da interpretação judicial $^{10}$. Cabe, portanto, avaliar a juridicização da função política dentro da Organização Mundial do Comércio.

Deve notar-se que este procedimento de juridicização principalmente do OSC ocorre em duas fases ${ }^{11}$. Uma primeira fase é marcada pela a multiplicação e o reforço das normas substanciais expressas nos acordos constitutivos da OMC. A segunda fase, que atualmente está em andamento, caracteriza-se pela evolução dos mecanismos de monitoramento e implementação das normas presentes nos acordos constitutivos ${ }^{12}$.

Na OMC, a fase jurisdicional ocorre com a instalação do Grupo especial e do Órgão de apelação que possuem as atividades

SALMON J. A. Le fait dans I'application du droit international, Recueil des cours - Academie de Droit International de La Haye, 1982, T.175, p. 342- 368; DUPUY Pierre-Marie, L'unité de l'ordre juridique international, Recueil des cours Académie de Droit International de La Haye, 2002, T.297, p. 428-479.

11 Cf. REICH Arie, From diplomacy to law: the juridicization of international trade relations, Northwestern Journal of International Law and Business, 19961997, n 17, p. 784-809.

12 VARELLA Marcelo D. The effectiveness of the Dispute Settlement Body of the World Trade Organization, Journal of trade law and policy, v. 8, n. 2. p. 100113. 
Artigo original

Hegemonia - Revista Eletrônica de Relações Internacionais do Centro Universitário Unieuro

ISSN: $1809-1261$

UNIEURO, Brasília, número 11, 2013, pp. 36-68

regulamentadas pelo ESC, atividades estas que guardam relação com o direito internacional. Em outras palavras, as atividades do OSC são fundamentadas em regras costumeiras internacionais. Isso implica, por exemplo, que na prática os membros do Órgão de apelação exercem atividades análogas àquelas exercidas pelos tribunais internacionais. Assim, a função jurisdicional internacional, independentemente da corte onde é praticada, é a mesma qual seja: "decidir de forma independente, imparcial, em conformidade com o devido processo legal e com a aplicação e a interpretação da regras estabelecidas pelos Tratados"13.

3.2 A análise da função jurisdicional do OSC

A função jurisdicional é caracterizada pelo dever de "dizer o direito" de "forma obrigatória". Analisando o ESC verifica-se que este reveste o OSC da função jurisdicional:

13 OMC. Forum public de l'OMC: comment I'OMC peut-elle aider à maîtriser la mondialisation? Genève : Secrétariat de I'OMC, 2007, p. 130. 
Artigo original

Hegemonia - Revista Eletrônica de Relações Internacionais do Centro Universitário Unieuro

ISSN: $1809-1261$

UNIEURO, Brasília, número 11, 2013, pp. 36-68

" [...] Os Membros reconhecem que esse sistema é útil para preservar direitos e obrigações dos Membros dentro dos parâmetros dos acordos abrangidos e para esclarecer as disposições vigentes dos referidos acordos em conformidade com as normas correntes de interpretação do direito internacional público"14.

Um órgão jurisdicional internacional deve apresentar três elementos principais: um primeiro estrutural, que diz respeito à composição do órgão; um critério formal, ou seja, está submetido a procedimentos e princípios amparados pelo direito internacional, e finalmente, um critério material que obriga o órgão a interpretar e a aplicar o direito internacional ${ }^{15}$. Verificaremos então se esses critérios estão presentes no OSC.

1- Critério estrutural

\footnotetext{
14 ESC, artigo 2, parágrafo 2

15 Cf. ASCENSIO Hervé. La notion de juridiction internationale en question. In. LA JURIDICTIONNALISATION DU DROIT INTERNATIONAL, actes du 36 colloque de la Société française pour le droit international, 12, 13 et 14 septembre 2002, Faculté des sciences juridiques, politiques et sociales de I'Université de Lille II. / [organisé par la] Société française pour le droit international, Université de Lille II, Paris, A. Pedone, 2003, p. 169 ; Fabri H.RUIZ, Le règlement des différends au sein de I'OMC: naissance d'une juridiction, consolidation d'un droit. IN Souveraineté étatique et marchés internationaux à la fin du $20^{\mathrm{e}}$ siècle. Mélanges en I'honneur de Philippe Kahn. Paris: Litec, 2000; BERTHELOT Erwan. La communauté européenne et le règlement des différends au sein de l'OMC, Université de Rennes, CEDRE, France : Ed. Apogée, 2001.
} 
Artigo original

Hegemonia - Revista Eletrônica de Relações Internacionais do Centro Universitário Unieuro

ISSN: $1809-1261$

UNIEURO, Brasília, número 11, 2013, pp. 36-68

O critério estrutural garante que o órgão possui os elementos essenciais capazes de garantir o exercício das funções de um "juiz internacional". Em outras palavras, esse critério garante que o OSC terá a imparcialidade e a independência no exercício de suas funções estabelecidas pelos Tratados da OMC.

Essa função de "juiz internacional" é materializada primeiramente quando o OSC tem a missão de esclarecer e interpretar as disposições dos Acordos da OMC. Em segundo, quando ocorre a publicação de suas recomendações sobre a questão em litígio e, finalmente, quando ele assegura o equilíbrio entre direitos e obrigações dos membros ${ }^{16}$.

Os princípios da imparcialidade e da independência são aplicados no momento da escolha dos membros que irão compor o Grupo especial e o Órgão de apelação. Esses princípios garantem principalmente que os membros que irão compor o órgão julgador não terão nenhuma espécie de vínculo com as partes litigantes. 0 ESC determina também que para a composição do Grupo especial, o Secretariado do OSC manterá uma lista de especialistas em áreas específicas ou de pessoas capazes de prestar auxílio ao Órgão de 
Artigo original

Hegemonia - Revista Eletrônica de Relações Internacionais do Centro Universitário Unieuro

ISSN: $1809-1261$

UNIEURO, Brasília, número 11, 2013, pp. 36-68

Solução de Controvérsias. Deste modo, o Grupo especial será composto por três pessoas dessa lista que serão referendadas pelas partes litigantes. Esses integrantes dos grupos especiais deverão atuar a título pessoal e não como representantes de governos ou de uma organização. Assim sendo, os Membros não Ihes fornecerão instruções nem procurarão influenciá-los com relação aos assuntos submetidos ao Grupo especial ${ }^{17}$.

A composição do Órgão de apelação é de sete membros permanentes e esses manterão também a imparcialidade e a independência dos governos ou das organizações de origem. Cabe esclarecer que os pareceres dos membros do Órgão de apelação são anônimos ${ }^{18}$. Percebe-se pelas constatações descritas acima que o OSC satisfaz o critério estrutural exigido a todo órgão jurisdicional.

2 - Critério formal

17 Cf. artigo 8, parágrafo 9 do ESC.

18 Cf. artigo 17 do ESC da OMC. 
Artigo original

Hegemonia - Revista Eletrônica de Relações Internacionais do Centro Universitário Unieuro

ISSN: $1809-1261$

UNIEURO, Brasília, número 11, 2013, pp. 36-68

O respeito ao critério formal permite a garantia dos princípios fundamentais como a igualdade entre as partes e, o devido processo legal capazes de conceder um julgamento justo às partes envolvidas no litígio.

O OSC adota um procedimento específico na resolução dos conflitos. Esses procedimentos são compostos por "métodos políticodiplomático" e por "métodos jurisdicionais". No método políticodiplomático tem-se a resolução de conflitos por meios diplomáticos. Esse método composto pelos bons ofícios, pela conciliação e pela mediação compõe a primeira fase do processo de resolução de conflitos do OSC. Convém ressaltar que essa primeira fase diplomática é obrigatória em todos os litígios e essa exigência se justifica porque uma resolução amigável do conflito é preferível ao litígio.

O procedimento jurisdicional se concretiza com o estabelecimento do Grupo especial ou do Órgão de apelação. A solicitação da instalação do Grupo especial marca a segunda fase do processo de resolução de conflitos do OSC. A reclamação deverá ser enviada por escrito ao OSC e ela deve conter a exposição dos motivos bem como a descrição das medidas contrárias aos acordos da OMC. 
Artigo original

Hegemonia - Revista Eletrônica de Relações Internacionais do Centro Universitário Unieuro

ISSN: $1809-1261$

UNIEURO, Brasília, número 11, 2013, pp. 36-68

Na prática, nessa segunda fase do processo de resolução de conflitos do OSC são aplicadas as seguintes regras próprias aos processos judiciais dos tribunais nacionais: necessidade de notificar e apresentar as demandas ao Estado que está sendo reclamado no OSC; possibilitar ao Estado reclamado o acesso ao processo, bem como concedê-lo prazo de resposta respeitando assim um processo com igualdade entre as partes e o direito a um julgamento justo. 0 relatório com as decisões do Grupo especial, após ser apresentado aos países litigantes, poderá ser contestado perante o Órgão de apelação, iniciando-se assim a terceira fase do processo de resolução de conflitos do OSC. Verificamos, portanto, que o OSC assegura às partes um julgamento justo revelando assim o cumprimento do critério formal exigido a todo órgão jurisdicional.

\section{3 - Critério material}

O critério material diz respeito à aplicação e à interpretação do direito internacional. Na prática, o cumprimento deste critério marcou uma evolução do processo de resolução de litígios na OMC. Essa evolução foi marcada pelas decisões tomadas em conformidade com 
Artigo original

Hegemonia - Revista Eletrônica de Relações Internacionais do Centro Universitário Unieuro

ISSN: $1809-1261$

UNIEURO, Brasília, número 11, 2013, pp. 36-68

os princípios do direito garantindo assim credibilidade às atividades do OSC.

O critério material significa também a obrigação do órgão jurisdicional de determinar a lei aplicável ${ }^{19}$ e, eventualmente, de resolver os conflitos de leis ${ }^{20}$. O OSC executa esse critério quando analisa e interpreta os acordos da OMC. Essa análise, por exemplo, ocorre quando um dos litigantes apresenta os motivos e os acordos desrespeitados pelo outro membro envolvido no conflito. Cabe assim ao OSC a análise e a competência para determinar se as medidas tomadas são descumpridoras de acordos da OMC e mesmo determinar se os acordos elencados por uma das partes é ou não aplicável ao litígio ${ }^{21}$.

Em diversas decisões do OSC verificou-se que o órgão recorre a outros acordos e normas do direito internacional tendo em vista os pontos lacunares dos acordos da OMC. Na verdade os acordos da OMC "são considerados como contratos incompletos e dessa forma, o

19 Ver : TRACHTMAN Joel P. , The domain of WTO dispute resolution, Harvard international law journal, 1999, Vol. 40, p. 337.

20 Sobre esse tema ver: Le pluralisme des objetifs, Hélène GAUDEMETTALLON, Le pluralisme en droit international privé: richesses et faiblesses, Recueil des cours - Académie de Droit International de La Haye, 2005, T. 312, p. 171ss. 21 Ver detalhes caso Brasil - Medidas referentes ao coco ralado, Órgão de apelação, WT/DS22/AB/R adotado em 20 março 1997 pelo OSC. 
Artigo original

Hegemonia - Revista Eletrônica de Relações Internacionais do Centro Universitário Unieuro

ISSN: $1809-1261$

UNIEURO, Brasília, número 11, 2013, pp. 36-68

Grupo especial e o Órgão de apelação são os administradores intermediários agindo para o bem comum dos Membros da OMC"22.

Dessa forma, o OSC tem a função de intérprete dos acordos da OMC levando em consideração as normas e princípios gerais do direito como, por exemplo, as normas estabelecidas pela Convenção de Viena sobre o direito dos Tratados de $1969^{23}$.

Nessa perspectiva, o OSC já estabeleceu o princípio da liberdade de interpretação dos acordos da OMC. Por exemplo, os casos EUA-Gasolina ${ }^{24}$ e EUA-Camarões ${ }^{25}$ são os dois exemplos clássicos que demonstram a atuação inovadora do OSC ao interpretar de forma teleológica os acordos da OMC.

No caso EUA-Gasolina, o OSC empregou essa forma teleológica ao interpretar o artigo XX do GATT de 1994. O OSC entendeu que as exceções contidas nesse artigo eram justificativas para o emprego

22 OMC. Forum public de l'OMC: comment I'OMC peut-elle aider à maîtriser la mondialisation? Genève: Secrétariat de I'OMC, 2007, p. 117 et Joel P. TRACHTMAN, The domain of WTO dispute resolution, Harvard international law journal, 1999, Vol. 40, p. 347-351.

23 Mais detalhes sobre a aplicação dessa Convenção pelo OSC ver: SEROIN Isabelle, L'application des règles d'interprétation de la Convention de Vienne sur le droit des traités dans le cadre de I'ALÉ, de I'ALÉNA, du GATT et de I'OMC, Revue juridique Thémis, 2000, vol. 34, n. 1, pag. 227-272.

24 EUA - Padrões para Gasolina Reformulada e Convencional, Órgão de apelação, WT/DS2/AB/R adotado em 29 abril 1996 pelo OSC.

${ }_{25}$ EUA - Camarões, Órgão de apelação, WT/DS58/AB/R adotado em 18 outubro 1998 pelo OSC. 
Artigo original

Hegemonia - Revista Eletrônica de Relações Internacionais do Centro Universitário Unieuro

ISSN: $1809-1261$

UNIEURO, Brasília, número 11, 2013, pp. 36-68

provisório de medidas discriminatórias ao comércio internacional. Da mesma forma, no caso EUA-Camarões, o Órgão de apelação concedeu uma interpretação extensiva ao conceito de "desenvolvimento durável e principalmente ao conceito de "recursos naturais não renováveis"26. O OSC utilizou Convenções externas aos acordos da OMC na fundamentação de sua decisão27.

Verifica-se que o OSC possui características ligadas ao jurisdictio - ou seja, é um órgão competente para "dizer o direito". Resta, no entanto, verificar que ele é capaz de cumprir outro critério próprio à função jurisdicional ${ }^{28}$ qual seja: - imperium - quer dizer, impor de forma obrigatória aos seus membros o direito da OMC.

4 A aplicação das decisões do OSC e a promoção do desenvolvimento sustentável

\footnotetext{
26 Mais detalhes ver $\S 129$ et 130 da decisão do Órgão de apelação : EUA Camarões.

27 O OSC fez por exemplo referência a outras convenções internacionais sobre recursos naturais como por exemplo, a Convenção das Nações Unidas sobre o direito do Mar de 1982.

28 Sobre a função jurisdicional ver mais detalhes: ASCENSIO Hervé. La notion de juridiction internationale en question. In. LA JURIDICTIONNALISATION DU DROIT INTERNATIONAL, actes du 36 colloque de la Société française pour le droit international, 12, 13 et 14 septembre 2002, Faculté des sciences juridiques, politiques et sociales de l'Université de Lille II. / [organisé par la] Société française pour le droit international, Université de Lille II, Paris, A. Pedone, 2003, p. 167.
} 
Artigo original

Hegemonia - Revista Eletrônica de Relações Internacionais do Centro Universitário Unieuro

ISSN: $1809-1261$

UNIEURO, Brasília, número 11, 2013, pp. 36-68

Nos tópicos precedentes, verificaram-se de forma teórica as atuações e a organização do Órgão de Solução de Controvérsias (OSC). Não resta dúvida de que esse Órgão dispõe de requisitos capazes de garantir os objetivos da OMC, dentre eles um comércio baseado no desenvolvimento sustentável. Convém, no entanto, analisar como na prática as decisões do OSC podem efetivamente concretizar a realização e a proteção de um meio-ambiente sustentável. Em outras palavras, é fundamental analisar como os Membros da OMC aplicam as recomendações e as decisões do OSC.

O OSC poderá contribuir na promoção de um meio-ambiente sustentável na medida em que puder dispor de mecanismos capazes de obrigar os seus Membros a modificarem ou removerem políticas contrárias aos objetivos da OMC.

Nas estatísticas publicadas pela OMC de 1 de Janeiro de 1995 até 28 fevereiro de 2013, 456 casos contestando a aplicação dos Acordos da OMC foram submetidos ao OSC. No total, uma média de 90 casos foram solucionados pelos canais puramente diplomáticos. Nesses casos não foi, portanto, acionada a via contenciosa, pois os membros resolveram a contenda amigavelmente. Por outro lado, 137 casos foram iniciados no OSC, mas, as queixas não tiveram 
Artigo original

Hegemonia - Revista Eletrônica de Relações Internacionais do Centro Universitário Unieuro

ISSN: $1809-1261$

UNIEURO, Brasília, número 11, 2013, pp. 36-68

prosseguimento. Merecem, no entanto, atenção aqueles casos que seguiram a via contenciosa. No presente artigo não é possível mencionarmos todos os casos. Serão mencionados apenas aqueles que tiveram desdobramento em várias fases do processo de contencioso do OSC até a efetiva adequação às normas da OMC. Poucos são ainda os casos com alcance ambiental. O mais importante, no entanto, é analisar os casos e os mecanismos desenvolvidos pelo OSC na implementação de suas recomendações e decisões.

Alguns casos demonstram como o OSC tem sido capaz de obrigar o cumprimento e o respeito dos acordos da OMC independente do poder econômico dos países envolvidos no litígio. Casos como: CE-hormônios (Canadá) (4.1) demonstra que é submetido ao OSC, litígios entre grandes potências econômicas. Da mesma forma, esse órgão tem possibilitado a participação de pequenos países como bem demonstra o caso: EUA-jogos (4.2). Por fim, cabe salientar o caso dos: Pneus (4.3) que para o cumprimento integral das determinações do OSC, o Brasil teve que recorrer a mais alta Corte brasileira. 
Artigo original

Hegemonia - Revista Eletrônica de Relações Internacionais do Centro Universitário Unieuro

ISSN: $1809-1261$

UNIEURO, Brasília, número 11, 2013, pp. 36-68

\subsection{Caso CE-hormônios (Canadá)}

Esse caso $^{29}$ opôs os EUA e Canadá, países reclamantes, à atual União Europeia (UE). Essa, invocando a segurança alimentar, e principalmente o princípio da precaução, proibiu a importação de carne e derivados de carne tratados com substâncias de efeito hormonal. Os EUA e o Canadá tentaram, em vão, resolver o conflito por meio de negociações com a UE. Foi assim solicitado a abertura de um Grupo Especial para analisar se a medida europeia violava os seguintes acordos: GATT, Medidas sanitárias e fitossanitárias (MSF) e - acordo sobre Obstáculos Técnicos ao Comércio (OTC). O Grupo Especial concluiu que as medidas europeias eram incompatíveis com os acordos da OMC. Decisão esta confirmada pelo Órgão de Apelação. Como consequência, os EUA e o Canadá obtiveram a autorização de suspender diversas vantagens das quais a UE era beneficiária. Após de Apelação, WT/DS26, 48/AB/R, adotado pelo OSC em 13 de fevereiro de 1998. 
Artigo original

Hegemonia - Revista Eletrônica de Relações Internacionais do Centro Universitário Unieuro

ISSN: $1809-1261$

UNIEURO, Brasília, número 11, 2013, pp. 36-68

essas suspensões sofridas pela UE, esta decidiu cumprir a decisão do OSC e editou a Diretiva 2003/74/CE. Na verdade, a nova diretiva suscitou diversos debates em torno no princípio da precaução e a UE continuou a proibir a entrada no mercado europeu de produtos alimentares tratados com hormônios. Fato este que suscitou nova demanda perante a OMC para se verificar a conformidade da Diretiva europeia com as normas da OMC. Esse contencioso obteve parcialmente fim em 2009 quando os EUA realizaram um acordo com a UE. O Canadá, porém não obteve acordo e mantém do direito de exercer retorsões ao bloco europeu.

Verifica-se que vários são os procedimentos existentes no OSC capazes de proporcionar a resolução de litígios entre os Membros da OMC.

\subsection{Caso EUA-Jogos de azar}

No contencioso EUA-Jogos de azar, os EUA fizeram oposição ao fornecimento transfronteiriço realizado por Antígua e Barbuda de serviços de jogos e de apostas. Os serviços fornecidos a distância pelas pequenas ilhas do Caribe, Antígua e Barbuda, foram proibidos 
Artigo original

Hegemonia - Revista Eletrônica de Relações Internacionais do Centro Universitário Unieuro

ISSN: $1809-1261$

UNIEURO, Brasília, número 11, 2013, pp. 36-68

pelas leis americanas. Proibição esta que em 2003 levou à constituição de um Grupo Especial no OSC para se analisar a compatibilidade das proibições com os compromissos americanos assumidos no âmbito do Acordo de Serviços da OMC (GATS). Essa primeira decisão do OSC no âmbito do comércio eletrônico confirmou em 2005 as alegações de Antígua e Barbuda e recomendou aos EUA a adaptação das leis americanas ao Acordo GATS. Mesmo depois de longo tempo para se decidir, os EUA não se adequaram imediatamente às recomendações do OSC. Assim, Antígua e Barbuda obtiveram o direito de retorsão no âmbito do GATS ou do Acordo de Propriedade Intelectual (TRIPS). Os EUA decidiram contestar as medidas de retorsão o que levou o estabelecimento de procedimento arbitral que fixou o montante em dólar da medida de retorsão a ser aplicada por Antígua e Barbuda. Mesmo se as partes ainda não chegaram a uma solução definitiva, o importante é que as partes continuam o processo de negociação. Os EUA iniciaram o processo de alteração dos compromissos específicos com o objetivo de excluir a oferta de jogos e apostas no seu território para assim refletir a intenção original do EUA quando das negociações do GATS. Os Estados Unidos entraram em negociações com os membros da OMC 
Artigo original

Hegemonia - Revista Eletrônica de Relações Internacionais do Centro Universitário Unieuro

ISSN: $1809-1261$

UNIEURO, Brasília, número 11, 2013, pp. 36-68

que poderiam ser afetados pela mudança. Assim, os EUA têm oferecido ajustes na intenção de substituir o compromisso no âmbito dos jogos por outros compromissos.

Esse caso é interessante no que se refere ao embate entre uma grande potência e países inexpressivos economicamente. Mais uma vez pode-se constatar a utilização das várias etapas do processo de negociação no OSC. A importante vitória desse contencioso é a comprovação de que o OSC está a serviço de TODOS os membros da OMC e principalmente a demonstração da necessária adaptação das normas nacionais aos Acordos da OMC.

\subsection{Caso dos Pneus recauchutados 30}

Este caso foi iniciado em 2005 quando a Comunidade Europeia (CE) -atualmente União Europeia - após não atingir êxito nas negociações com o Brasil solicitou a instalação de um Grupo especial ao OSC. A CE questionou na OMC a proibição de importação de pneus recauchutados estabelecida pela Portaria brasileira SECEX 8 de 2000.

30 Brasil-pneus recauchutados, Órgão de apelação, WT/DS332/AB/R, adotado em 3 dezembro 2007 pelo OSC. 
Artigo original

Hegemonia - Revista Eletrônica de Relações Internacionais do Centro Universitário Unieuro

ISSN: $1809-1261$

UNIEURO, Brasília, número 11, 2013, pp. 36-68

A CE também alegou que o Brasil concedia exceção aos países do MERCOSUL que podiam exportar esses pneus para o Brasil. Assim CE alegou que essas medidas brasileiras eram contrárias as obrigações estabelecidas pelo GATT. O Brasil defendeu-se com base no artigo $\mathrm{XX}$ do GATT alegando que a entrada de pneus recauchutados no Brasil produziria uma ameaça ao meio ambiente e à saúde pública; no que toca à medida de exceção ao MERCOSUL, o Brasil alegou que a mesma era permitida segundo o artigo XXIV do GATT. A decisão do Grupo especial, também confirmada pelo Órgão de apelação, foi de reconhecer válidos os argumentos brasileiros sobre o direito de estabelecer medidas protecionistas por serem consideradas ameaças ao meio ambiente e à saúde pública. Porém, o Órgão de apelação não aprovou as formas como as medidas foram aplicadas pelo Brasil. Ele entendeu que na aplicação da restrição o Brasil agia de forma discriminatória, pois como explica um autor "a proibição brasileira excetuava os importadores brasileiros que obtinham medidas liminares perante o Poder Judiciário, bem como as importações provenientes do MERCOSUL". 31 O OSC concluiu que as 100 casos na OMC: a experiência brasileira em solução de controvérsias. Política Externa, v. 20, n. 4, p. 121-134, 2012. 
Artigo original

Hegemonia - Revista Eletrônica de Relações Internacionais do Centro Universitário Unieuro

ISSN: $1809-1261$

UNIEURO, Brasília, número 11, 2013, pp. 36-68

proibições estabelecidas pelo Brasil eram incompatíveis com as normas da OMC e, portanto, o país deveria rever sua legislação nacional. Em 25 de setembro de 2009 o Brasil comunicou ao OSC o cumprimento integral das recomendações da OMC. Assim, verificamos o reconhecimento e o respeito das normas estabelecidas pelo sistema multilateral.

5 Conclusão

Verifica-se, portanto, que o OSC dispõe de mecanismos capazes de interpretar os acordos da OMC e principalmente de promover o cumprimento integral de suas decisões ou recomendações. Cabe ressaltar que os membros da OMC ainda não aplicam de forma completa e imediata as decisões ou recomendações da OMC. Essa aplicação ocorre de forma lenta e gradual após sucessivas negociações. Verifica-se, no entanto que cada vez mais os membros têm se inserido no processo, mesmo que lento, de adaptação das legislações internas a obrigações assumidas no âmbito da OMC. A juridicialização do OSC tem cada vez mais contribuído para essa 
Artigo original

Hegemonia - Revista Eletrônica de Relações Internacionais do Centro Universitário Unieuro

ISSN: $1809-1261$

UNIEURO, Brasília, número 11, 2013, pp. 36-68

efetivação da aplicação das obrigações da OMC nos ordenamentos internos dos membros.

O tema de desenvolvimento sustentável é cada vez mais presente nos fóruns de discussão da OMC e nos litígios interpostos ao OSC. Esse tema revela uma acentuada dimensão e assim é de fundamental importância que ele seja abordado em um fórum multilateral capaz de impor aos seus membros a observância de suas normas.

6 Referências

ASCENSIO Hervé. La notion de juridiction internationale en question. IN. La Juridictionnalisation du Droit international, actes du 36 colloque de la Société française pour le droit international, 12, 13 et 14 septembre 2002, Faculté des sciences juridiques, politiques et sociales de l'Université de Lille II. / [organisé par la] Société française pour le droit international, Université de Lille II, Paris, A. Pedone, 2003.

BERTHELOT Erwan. La communauté européenne et le règlement des différends au sein de I'OMC, Université de Rennes, CEDRE, France : Ed. Apogée, 2001

CAVARÉ L, La notion de juridiction internationale. Annuaire Français de droit international, 1956, p. 496-509.

D'AMBRA Dominique. L'objet de la fonction juridictionnelle, dire le droit et trancher les litiges. Paris : Librairie générale de droit et de jurisprudence, 1994. 
Artigo original

Hegemonia - Revista Eletrônica de Relações Internacionais do Centro Universitário Unieuro

ISSN: $1809-1261$

UNIEURO, Brasília, número 11, 2013, pp. 36-68

DUPUY Pierre-Marie, L'unité de l'ordre juridique international, Recueil des cours - Académie de Droit International de La Haye, 2002, T.297.

FABRI, H. Ruiz, Le règlement des différends au sein de I'OMC: naissance d'une juridiction, consolidation d'un droit. IN Souveraineté étatique et marchés internationaux à la fin $d u 20^{e}$ siècle. Mélanges en l'honneur de Philippe Kahn. Paris : Litec, 2000.

GAUDEMET-TALLON, Hélène Le pluralisme en droit international privé: richesses et faiblesses, Recueil des cours - Académie de Droit International de La Haye, 2005, T. 312, p. 171ss.

OMC. Forum public de I'OMC: comment I'OMC peut-elle aider à maîtriser la mondialisation? Genève : Secrétariat de I'OMC, 2007.

OMC/OSC, EUA - Padrões para Gasolina Reformulada e Convencional, Órgão de apelação, WT/DS2/AB/R adotado em 29 abril 1996 pelo OSC.

OMC/OSC, Brasil - Medidas referentes ao coco ralado, Órgão de apelação, WT/DS22/AB/R adotado em 20 março 1997 pelo OSC.

OMC/OSC, CE- medidas que afetam a carne e derivados de carne (hormônios). Órgão de Apelação, WT/DS26, 48/AB/R, adotado pelo OSC em 13 de fevereiro de 1998.

OMC/OSC, EUA - Camarões, Órgão de apelação, WT/DS58/AB/R adotado em 18 outubro 1998 pelo OSC.

OMC/OSC, Brasil-pneus recauchutados, Órgão de apelação, WT/DS332/AB/R, adotado em 3 dezembro 2007 pelo OSC.

PEREIRA, Celso de Tarso; COSTA, Valéria Mendes; ARAUJO, Leandro Rocha. 100 casos na OMC: a experiência brasileira em solução de controvérsias. Política Externa, v. 20, n. 4, p. 121-134, 2012.

PIRES, Camila Faria Braga. Comércio e meio ambiente e a Organização Mundial do Comércio. Revista Eletrônica de Direito 
Artigo original

Hegemonia - Revista Eletrônica de Relações Internacionais do Centro Universitário Unieuro

ISSN: $1809-1261$

UNIEURO, Brasília, número 11, 2013, pp. 36-68

Internacional (CEDIN), 2007, Disponível em: < http://www.cedin.com.br/revistaeletronica/indice.htm>, acesso em 24 abr. 2012.

REICH Arie, From diplomacy to law: the juridicization of international trade relations, Northwestern Journal of International Law and Business, 1996-1997, n 17, p. 831-839.

SALMON J. A. Le fait dans l'application du droit international, Recueil des cours - Academie de Droit International de La Haye, 1982, T.175, p. 342- 368.

SANTULLI Carlo, Qu'est-ce qu'une juridiction internationale ? Des organes répressifs internationaux à I'ORD, Annuaire Français de droit international, 2000, Vol. XLVI, p. 58-81.

SEIFFERT, Mari Elizabete Bernardini. Gestão ambiental : instrumentos, esferas de ação e educação ambiental. São Paulo: Atlas, 2011.

SEROIN Isabelle, L'application des règles d'interprétation de la Convention de Vienne sur le droit des traités dans le cadre de I'ALÉ, de I'ALÉNA, du GATT et de l'OMC, Revue juridique Thémis, 2000, vol. 34, n. 1, p. 227-272.

SWEET Stone, Judicialization and the construction of governance, Comparative Political Studies, 1999, Vol. 32, n² 2, p. 147-184.

TRACHTMAN Joel P. The domain of WTO dispute resolution, Harvard international law journal, 1999, Vol. 40, p. 337.

VARELLA, Marcelo Dias. O acúmulo de lógicas distintas no Direito Internacional: conflitos entre comércio internacional e meio ambiente. IN Desafios do direito ambiental no século XXI, 2005.

- The effectiveness of the Dispute Settlement Body of the World Trade Organization, Journal of trade law and policy, v. 8, n. 2. 